\title{
Living Well with Diabetes: a randomized controlled trial of a telephone-delivered intervention for maintenance of weight loss, physical activity and glycaemic control in adults with type 2 diabetes
}

Elizabeth G Eakin ${ }^{1 *}$, Marina M Reeves ${ }^{1}$, Alison L Marshall², David W Dunstan ${ }^{1,3}$, Nicholas Graves², Genevieve N Healy ${ }^{1}$, Jonathan Bleier ${ }^{1}$, Adrian G Barnett ${ }^{2}$, Trisha O'Moore-Sullivann ${ }^{4}$, Anthony Russell ${ }^{4}$, Ken Wilkie ${ }^{5}$

\begin{abstract}
Background: By 2025, it is estimated that approximately 1.8 million Australian adults (approximately $8.4 \%$ of the adult population) will have diabetes, with the majority having type 2 diabetes. Weight management via improved physical activity and diet is the cornerstone of type 2 diabetes management. However, the majority of weight loss trials in diabetes have evaluated short-term, intensive clinic-based interventions that, while producing short-term outcomes, have failed to address issues of maintenance and broad population reach. Telephone-delivered interventions have the potential to address these gaps.

Methods/Design: Using a two-arm randomised controlled design, this study will evaluate an 18-month, telephone-delivered, behavioural weight loss intervention focussing on physical activity, diet and behavioural therapy, versus usual care, with follow-up at 24 months. Three-hundred adult participants, aged 20-75 years, with type 2 diabetes, will be recruited from 10 general practices via electronic medical records search. The SocialCognitive Theory driven intervention involves a six-month intensive phase (4 weekly calls and 11 fortnightly calls) and a 12-month maintenance phase (one call per month). Primary outcomes, assessed at 6, 18 and 24 months, are: weight loss, physical activity, and glycaemic control ( $\mathrm{HbA1c}$ ), with weight loss and physical activity also measured at 12 months. Incremental cost-effectiveness will also be examined. Study recruitment began in February 2009, with final data collection expected by February 2013.

Discussion: This is the first study to evaluate the telephone as the primary method of delivering a behavioural weight loss intervention in type 2 diabetes. The evaluation of maintenance outcomes ( 6 months following the end of intervention), the use of accelerometers to objectively measure physical activity, and the inclusion of a costeffectiveness analysis will advance the science of broad reach approaches to weight control and health behaviour change, and will build the evidence base needed to advocate for the translation of this work into population health practice.
\end{abstract}

Trial Registration: ACTRN12608000203358

\footnotetext{
* Correspondence: e.eakin@sph.uq.edu.au

${ }^{1}$ The University of Queensland, Level 3 Public Health Building, School of Population Health, Cancer Prevention Research Centre, Herston Road, Herston, QLD, Australia

Full list of author information is available at the end of the article
} 


\section{Background}

\section{Type 2 diabetes - a population health problem}

The rapid increase in the prevalence of type 2 diabetes, obesity and associated complications is a major public health problem. In Australia, data from the 1999-2000 AusDiab study estimated that approximately 1 million (7.4\%) Australian adults aged 25 years and over have type 2 diabetes [1], with approximately $85 \%$ being overweight or obese [2]. The growing epidemics of type 2 diabetes and obesity have been concurrent, with the prevalence of both doubling over the past 20 years [1]. The prevalence of type 2 diabetes is predicted to increase dramatically over the next few decades; projections are that by 2030, $8.4 \%$ Australian adults aged 20-79 will have the disease [3]. Similar rapidly increasing prevalence estimates have been reported for the UK [3], USA $[3,4]$ and other developed and developing countries [3].

Identified as the seventh leading cause of death among Australian adults, type 2 diabetes is a major cause of premature mortality and morbidity due to cardiovascular, renal, ophthalmic and neurological disease [5]. Data from the DiabCost Australia study, which assessed the total costs of type 2 diabetes to the health care system, society, government and carers, estimated that $\$ 3$ billion a year is spent treating type 2 diabetes [6]. Since the burden of illness associated with type 2 diabetes increases with the onset of microvascular and macrovascular complications [6], there is high priority for effective and sustainable strategies to slow or prevent the onset of complications. The value of achieving glycaemic control is underscored by the landmark findings of the UK Prospective Diabetes Study, a 10 year observational follow-up in patients with diabetes, whereby each $1 \%$ reduction in glycosylated haemoglobin (HbA1c) was associated with a $14 \%$ reduction in myocardial infarction, a $37 \%$ reduction in microvascular events, and a $21 \%$ reduction in diabetes-related mortality [7]. This is of particular importance for people with type 2 diabetes since coronary heart disease is responsible for about $70 \%$ to $80 \%$ of deaths in this population [8].

Lifestyle factors that adversely affect energy balance (physical inactivity and over-nutrition) play a major role in the development of both type 2 diabetes and obesity $[9,10]$. The importance of weight management, by means of a healthy, energy-restricted diet and a physically active lifestyle, is considered to be the primary approach in the treatment of overweight and obesity $[11,12]$ and is widely acknowledged as a cornerstone of the management of type 2 diabetes and its related morbidities [13]. There is also evidence that many of the traditional pharmacologic approaches frequently used to treat diabetes contribute to weight gain [14]. Weight loss or weight management is an important therapeutic task for most people with type 2 diabetes, not only for improved glycaemic control but also for reducing cardiovascular disease (CVD) risk [13]. A modest weight loss of $5-10 \%$ of body weight has been associated with improvements in fasting plasma glucose, HbA1c, insulin, lipid levels, and blood pressure [10]. In addition, there is compelling epidemiologic and experimental evidence that physical activity confers substantial protection against CVD and premature mortality in those with type 2 diabetes, independent of weight loss, through its favourable effects on blood pressure, blood glucose, insulin sensitivity, lipid profile, fibrinolysis, endothelial function and inflammatory defence systems $[15,16]$.

At present in Australia, type 2 diabetes is managed primarily in the general practice setting (primary care). In addition to medication management and monitoring of glycaemic control, this may include brief lifestyle advice from General Practitioners (GPs), and for some, a Diabetes Care Plan that includes referral for a limited number of visits to diabetes educators, dietitians, exercise physiologists and other allied health professionals. Given the challenge of health behaviour change and weight loss, and the need for ongoing assistance to maintain such changes, approaches that work in concert with primary care are needed, with such approaches involving more behaviourally-focussed and longer-term self-management supports [17].

\section{Lifestyle management and weight loss intervention trials in type 2 diabetes}

There is a large literature on lifestyle management and weight loss interventions in type 2 diabetes, including the current landmark Look AHEAD trial, which is evaluating an intensive four-year weight loss intervention to reduce cardiovascular morbidity and mortality $[18,19]$. Across numerous studies, there is clear evidence that intensive lifestyle interventions involving reduced energy (and fat) intake, regular physical activity, cognitive behaviour therapy and frequent participant contact will produce significant behavioural improvements, as well as weight loss (5-7\% of body weight) and concomitant improvements in glycaemic control and dyslipidaemia $[10,20,21]$. However, there are a number of gaps in this literature that make its findings less relevant to informing a population-based approach to the lifestyle management of type 2 diabetes. First, the majority of trials have evaluated intensive, clinicbased interventions that are similar to the diabetes education programs offered through hospitals as part of clinical management. While these clinic-based interventions are effective [22], few patients with type 2 diabetes take part in such programs [23]. Second, very few studies include a post-intervention follow-up assessment to determine whether improvements are maintained longer term $[24,25]$. 


\section{Broad reach weight loss and lifestyle intervention trials}

A number of recent studies have evaluated weight loss interventions delivered via telephone, tailored print and the internet [26-31]. Of note are two recent studies which have evaluated a telephone-delivered approach for initiation and maintenance of weight loss [29,31]. One study observed similar short-term weight loss at 6 -months for both face-to-face $(8.9 \%)$ and telephonedelivered (7.7\%) interventions [29]. In the other trial, following initial weight loss at 6 months, small but statistically non-significant regain in weight was observed for those in the 12-month telephone and face-to-face maintenance contact groups, which was significantly less than the regain observed in the control group [31].

Telephone-delivered interventions have the potential for widespread and cost-effective population reach, and have been widely researched [32-38]. A systematic review of 26 telephone-delivered physical activity and dietary behaviour intervention studies found very strong support for their efficacy to produce short-term behavioural changes in both people with and without chronic conditions, with 20 of 26 studies reporting significant behavioural improvements immediately post-intervention [39]. Interventions lasting six to 12 months and those including 12 or more calls produced the most favourable outcomes. Our own work in this area has shown telephone-delivered interventions to be effective in promoting both initiation and maintenance $[40,41]$ of dietary change, as well as demonstrating cost-effectiveness [42].

\section{Purpose}

This paper describes the methods of the Living Well with Diabetes trial which is evaluating a telephonedelivered behavioural weight loss intervention focussing on physical activity, diet and behavioural therapy in adults with type 2 diabetes. To promote maintenance the 18 month intervention has an intensive first 6 months focussed on initiation of behaviour change, followed by 12 months focussed on enhancing/supporting maintenance. Measurement at baseline, six, 12, 18, and 24 months allows for assessment of initiation and maintenance of change - a major contribution of the study to the evidence base on broad reach interventions to support weight loss and lifestyle management in type 2 diabetes.

\section{Methods/Design Study design}

Living Well with Diabetes is a two-arm randomised controlled trial evaluating a telephone-delivered behavioural weight loss intervention versus usual care in adults with type 2 diabetes. Ethical approval was granted from The University of Queensland Behavioural and Social Sciences Ethical Review Committee.

\section{Setting}

Participants are recruited from general practices in the city of Logan (population 270,000), a large ethnically and socioeconomically diverse community in Queensland, Australia, which sits 35 kilometres from Brisbane (the state capital), and an urban centre of 1.8 million residents.

\section{Practice sampling and recruitment}

General practices are recruited from the Southeast Primary Health Care Network (SPHN), a state and federally funded organization that provides administrative, technical and professional development/educational support to local area practices. At study commencement, SPHN supported 76 practices. The study will recruit 10 practices over two years, with approximately 30 adults enrolled from each practice. To ensure an adequate patient sampling frame from each practice, practices are ranked in order of descending number of GPs, with the largest practices approached first on a rolling basis until 10 practices (or the required sample size of 300 participants) consent to participate. Practices are initially contacted by telephone to determine whether electronic medical records can be used to perform patient searches by medical condition, and whether approximately 200 patients with type 2 diabetes can be identified. Eligible practices are sent an invitation letter and study brochure. This is followed-up by a phone call from a GP working within the SPHN (author KW), and a practice visit from the project manager to solicit consent.

\section{Patient sampling and recruitment}

Within practices, electronic medical records are searched for potentially eligible patients. Eligibility is based on: diagnosed type 2 diabetes; aged 20-75 years; and having a listed telephone number. The lists of potentially eligible participants are initially screened by treating GPs for the following contraindications to an unsupervised physical activity and weight loss intervention: active heart disease, breathing problems requiring hospitalisation in the past 6 months, undergoing dialysis, taking Warfarin, diabetic complications such as severe neuropathy or retinopathy, planning a knee or hip replacement in the next 12 months, regular use of a mobility aid or pregnant. In addition, GPs are asked to screen out those who are undergoing cancer treatment (excluding hormone therapy), those from non-English speaking backgrounds and those with significant difficulty with written materials or with hearing problems that would make telephone contact prohibitive.

Eligible patients, based on GP screening, receive a letter from their GP informing them of the study, along with a study brochure and an expression of interest form with a return, pre-paid envelope. Patients not 
returning the form within two weeks receive a follow-up phone call from practice staff. Those patients returning the expression of interest form and those providing verbal consent to contact are posted a study information sheet and consent form. They then receive a call from study staff during which a detailed explanation of the study is provided, patients are re-screened for eligibility based on the same criteria as GPs (to account for variation in GP screening), and some additional exclusion criteria - current or planned (next 12-months) use of weight loss medications (e.g. Xenical, Reductil), and previously had or planning bariatric surgery. During this call, participants are also screened for self-reported baseline levels of physical activity and weight, and are excluded from study participation if they meet or exceed physical activity guidelines (30 minutes of moderate to vigorous physical activity on five or more days/week [43] AND are not overweight (defined as a body mass index [weight in kilograms/height in metres $^{2}$ ] of $<25.0$ $\mathrm{kg} / \mathrm{m}^{2}$ ) [44]. In addition, for those with a self-reported $\mathrm{BMI} \geq 45 \mathrm{~kg} / \mathrm{m}^{2}$, suitability for participation in unsupervised weight loss is confirmed from their GP. Consent to participate in the study is then sought from those considered eligible. De-identified data on eligible nonparticipants is obtained from medical records to compare demographic (age and sex) characteristics of participants and non-participants.

\section{Randomisation}

Following baseline data collection, allocation to study groups (telephone intervention or usual care) is conducted using the method of minimization to ensure equal group balance across factors likely to impact on primary study outcomes [45,46]. Minimisation factors based on baseline data collection include: gender, age (<55 years; $\geq 55$ years), BMI $\left(<40 \mathrm{~kg} / \mathrm{m}^{2} ; \geq 40 \mathrm{~kg} / \mathrm{m}^{2}\right)$, HbA1c (<8\%; $\geq 8 \%)$, physical activity level (meeting guidelines of at least 150 minutes/week and 5 or more sessions; not meeting guidelines) [47], and diabetes management (insulin or combination therapy; traditional oral hypoglycaemic medications; new glucose-lowering medications (e.g. Byetta, Januvia); lifestyle alone). Allocation is performed using the free Minim computer software [48] and conducted by a research assistant with minor involvement in participant recruitment. The timeframe from participant recruitment to group allocation ranges from approximately three to eight weeks to allow for extensive baseline data collection (see Data Collection section below), and not all minimisation factors are known at recruitment (e.g. HbA1c level, diabetes management). Therefore, the ability for the staff member to predict with certainty, the allocation of participants at recruitment, a criticism of the minimisation method [46], is near impossible.

\section{Usual care}

In order to minimise attrition over the 24-month study duration, participants in the usual care group receive a thank you letter and brief summary following each assessment. At baseline, 6-, 12- and 18-months they are also posted standard, off-the-shelf diabetes self-management education brochures (from Diabetes Australia) with information on diabetes education and a variety of health behaviours. These are consistent with the materials generally given to patients as part of their usual diabetes care. GPs for all patients in the study are also sent brief summaries of their patients' assessment results.

\section{Telephone-delivered weight loss intervention}

The weight loss intervention, delivered entirely over the telephone, uses a combined approach of increasing physical activity, reducing energy intake and behavioural therapy $[11,12]$. It is based on current evidence for initiation and maintenance of weight loss and clinical practice guidelines for the management of overweight/ obesity and type 2 diabetes. Participants receive a detailed workbook at the commencement of the intervention and up to 27 telephone calls over 18 months, to support both initiation and maintenance of weight loss. Call frequency is somewhat flexible, so that it can be tailored to the needs of the participant. For example, an extra weekly call might occur during a period of relapse.

Intervention targets for physical activity, dietary intake and weight loss are consistent with management goals for type 2 diabetes [10], with the aim to reduce glycosylated haemoglobin (HbA1c) to less than 7\% [11,49,50]. As described in detail below, participants work with their telephone counsellor to identify small, gradual changes to physical activity and dietary intake and that are able to be maintained long-term, rather than large and highly restrictive changes which are less likely to be maintained [11,51], as described below. Participants are encouraged to aim for moderate weight loss of $5-10 \%$ of initial body weight $[10,21]$, with a loss of $1-2 \mathrm{~kg}$ per month.

\section{Physical activity}

A target of 210 minutes per week (30 minutes every day) of moderate-intensity, planned activity is encouraged, consistent with the level of physical activity necessary to promote weight loss [49]. Given evidence suggesting that even higher levels of activity (i.e., 60 minutes/day) may be necessary for weight loss maintenance [52], those who can do more activity will be encouraged to work towards this during the maintenance phase. The telephone counsellor works with participants to first identify types of activities that they enjoy and can be easily incorporated into their lifestyle (e.g., walking), rather than providing a structured exercise program [11,53]. As most participants are relatively 
inactive at baseline, increases in physical activity are initially small and gradually increase towards the goal of 30 minutes per day of moderate-to-vigorous intensity activity [49].

Resistance exercise (2-3 sessions/week) is also encouraged, as strength training has benefits for glycaemic control [54] and is consistent with the physical activity guidelines for older adults [55]. Participants are provided with a resistance band, and detailed photographs and instructions are included in the workbook with guidelines on the number of sets and repetitions of each exercise, along with options for progression.

In addition to daily planned physical activity, participants are encouraged to take opportunities to be active in and around their homes and workplaces (e.g. gardening, housework, taking the stairs), and to reduce sitting time (i.e., to get up and move every 30 minutes and to aim for no more than 2 hours/day of screen time outside of work). This is consistent with evidence on the health benefits conferred by light-intensity activity [56-58], and with newer evidence on the cardio-metabolic consequences of too much sitting $[59,60]$.

Diet

Participants are encouraged to reduce energy intake by $2,000 \mathrm{~kJ}$ per day through individualised advice to allow for specific food preferences and approaches $[10,12,61]$. That is, the intervention does not use meal replacements or structured meal plans. Specific macronutrient compositions are not prescribed (e.g. high protein/low carbohydrate or high carbohydrate/moderate protein) as evidence on long-term maintenance of weight loss has shown similar outcomes for both types of diet [62-64]. A low fat diet $(<30 \%)$ is encouraged as this has been associated with long-term weight loss maintenance [52], as are a saturated fat intake of $<7 \%$ of energy and fibre intake of 25 grams/day for women and 30 grams/day for men, consistent with dietary recommendations for people with type 2 diabetes to reduce risk factors for cardiovascular disease [65]. Strategies to reduce energy intake include - improving portion control (by reducing portion size or number of serves) and lowering energy density (by increasing intakes of low energy foods such as fruits and vegetables and reducing intake of energy dense foods such as high fat foods). Regular meal patterns with an emphasis on eating breakfast are promoted [66].

\section{Behavioural therapy}

Behaviour change strategies and principles used to guide the intervention are derived from Social Cognitive Theory (SCT) [18], specifically developing knowledge and skills related to the SCT constructs of self-efficacy, social support and outcome expectancies. The matrix in Table 1 and the text below describe the way in which these are operationalized. No single behaviour strategy has been shown to be better than any other in terms of effects on weight loss, and thus multi-modal strategies are used [11,12]; although some strategies (i.e., self-monitoring) have been associated with better weight loss maintenance outcomes [67]. Behaviour change skills emphasised in this intervention include: self-monitoring, goal setting, problem solving, social support, stimulus control, positive self-talk, and self-reward.

Participants are provided with self-monitoring 'trackers,' to monitor their daily physical activity and food intake, and are encouraged to weigh themselves once to twice weekly. Participants are provided with a pedometer to monitor daily steps and with a set of digital scales to monitor their body weight.

Participants are encouraged to set small, measurable and achievable health behaviour change and weight loss goals that facilitate a sense of confidence and mastery that can be built upon throughout the intervention and hence build self-efficacy. These are recorded on a large, reusable refrigerator magnet. Problem solving is used to help participants identify barriers to their behaviour change goals and identify strategies and solutions to overcome these.

Participants are encouraged to identify a broad array of possible supports for weight loss (e.g., from family and friends co-workers, the general practitioner, neighbourhood or community programs) and to set specific goals for drawing upon these [68]. Stimulus control (or behaviour cue) techniques are used to create more supportive environments for health behaviour change and weight loss (e.g. keeping problem foods out of the house; putting left-overs in the freezer immediately; leaving walking shoes by the bedside). Positive self-talk (e.g. focussing on what has been achieved rather than what has been given up) is encouraged as a means of addressing habitual negative thinking [69], and selfrewards for goal attainment are promoted to reinforce behaviour change.

\section{Telephone counsellor background and training}

All telephone counsellors have at least bachelor's level training in nutrition and dietetics; some have also completed a dual-degree in exercise physiology. They undergo one month of intensive training in study protocols and a motivational interviewing approach to health behaviour counselling [70] (including role plays with study investigators). Telephone counsellors have ongoing quality assurance checks via randomly taped telephone calls and fortnightly clinical supervision meetings. In addition, call attempts, completions and duration are tracked, and a call content checklist completed after each call to inform an evaluation of intervention fidelity. To the extent possible, the same telephone counsellor remains with participants throughout the duration of the intervention to facilitate rapport and continuity of care. 
Table 1 Theory matrix

\begin{tabular}{ll}
\hline Social-Cognitive Theory Constructs & Operationalization \\
\hline Self-efficacy & Realistic and measurable goal-setting \\
& Assessing confidence \\
& Self-monitoring \\
& Practicing positive self-talk \\
Social support & Developing a support network (family/friends/others) \\
& Setting goals around using supports \\
Outcome expectancies & Benefits and barriers to health behaviour change \\
& Problem-solving approach to addressing barriers \\
& Rewards for goal attainment \\
\hline
\end{tabular}

\section{Intervention procedures}

Intervention delivery is guided by a patient-centred, chronic disease self-management intervention model used in previous trials (Figure 1) [37,71], and by techniques of motivational interviewing [70]. An iterative process is used in each call: it draws upon repeated assessment of study outcomes and participant self-monitoring; feedback is provided in relation to study targets for weight, dietary intake and physical activity, and consistent with a motivational interviewing approach, this feedback highlights the discrepancy between participant goals and their current health behaviours; collaborative goals for weight, physical activity and dietary change are set with the telephone counsellor, with an emphasis on achievability and measurability. Each intervention contact results in a behaviourally-specific Action Plan that specifies exactly what is to be done and when; barriers and supports are identified; confidence is assessed and problem-solving is discussed as necessary. These steps are repeated during intervention calls, with goals being adjusted as necessary.

A semi-structured approach to both the content and the order in which intervention targets are addressed is used to guide intervention delivery (see Table 2). However, consistent with the motivational interviewing approach, the intervention is tailored to each participant, with an initial focus on targets in which she/he is most motivated and most confident in changing.

Phase 1 (month 1) The first month of the intervention involves up to four weekly calls, with a focus on building rapport (e.g. providing feedback on the baseline assessment and understanding what the participant wants to

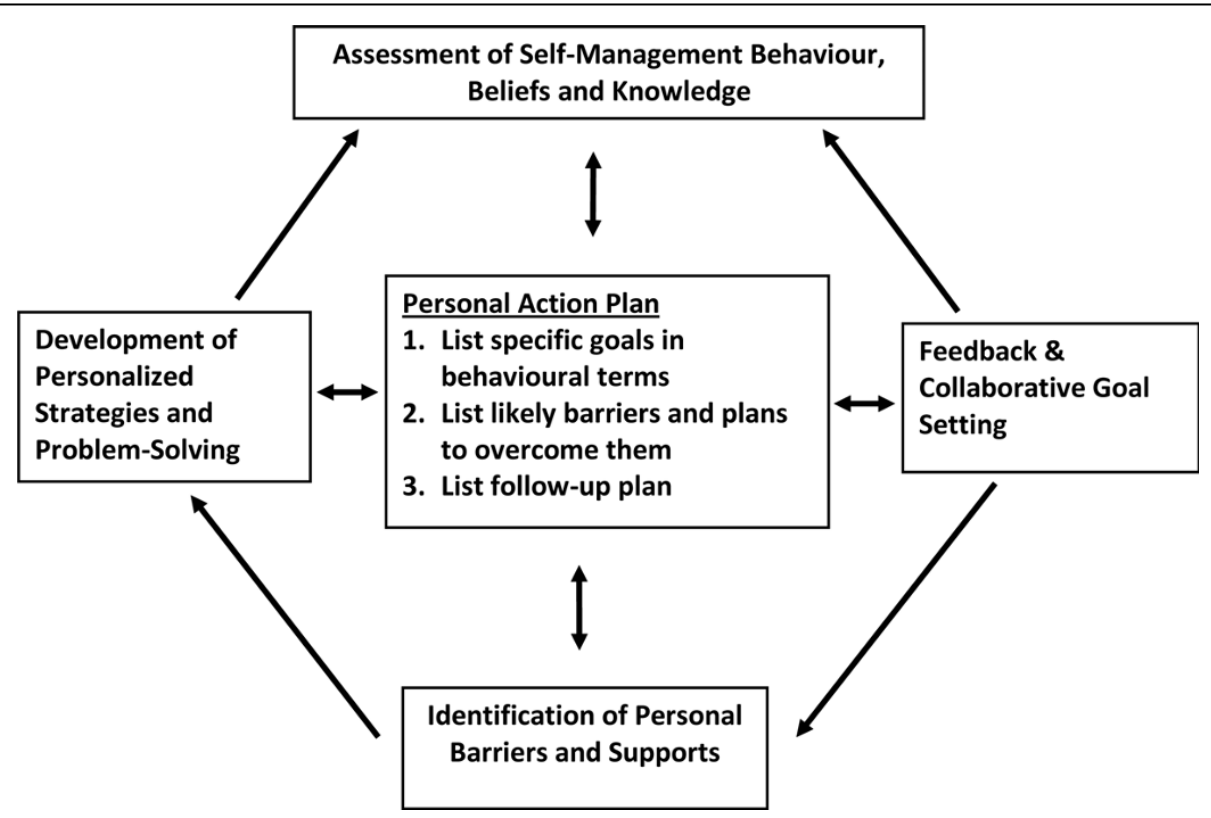

Figure 1 Chronic Disease Self-Management Intervention Model. 
Table 2 Telephone Intervention Overview: Call Frequency and Content

\begin{tabular}{|c|c|c|}
\hline $\begin{array}{l}\text { Intervention stage } \& \text { call } \\
\text { frequency }\end{array}$ & Purpose & Content \\
\hline $\begin{array}{l}\text { Phase 1: } \\
\text { (Month 1) } \\
4 \text { weekly calls }\end{array}$ & $\begin{array}{l}\text { Building rapport } \\
\text { Education } \\
\text { Skill-building }\end{array}$ & $\begin{array}{l}\text { Program introduction/explanation } \\
\text { Participant overarching program goals } \\
\text { Feedback on baseline assessment } \\
\text { Review \& goal-setting: } \\
\text { Weight loss: benefits, energy balance, realistic targets, portion sizes, } \\
\text { recommended } \\
\text { serves, reducing fat intake } \\
\text { Behaviour change skills: self-monitoring, goal-setting } \\
\text { Begin use of scale, pedometer and food diary }\end{array}$ \\
\hline $\begin{array}{l}\text { Phase 2: } \\
\text { (Months 2-6) } \\
11 \text { fortnightly calls }\end{array}$ & $\begin{array}{l}\text { Behaviour change } \\
\text { Weight loss } \\
\text { Skill-building }\end{array}$ & $\begin{array}{l}\text { Review \& goal-setting: } \\
\text { Physical activity: planned activity, incidental activity, sitting time, } \\
\text { strength training } \\
\text { Diet: reducing energy intake (choosing lower energy foods, swapping } \\
\text { higher energy } \\
\text { foods for lower energy foods, decreasing intake of high energy foods/ } \\
\text { drinks), eating } \\
\text { habits, food labels, modifying recipes } \\
\text { Behaviour change skills: rewards, behavioural cues, barriers and supports } \\
\text { Progress review at } 3 \text { months }\end{array}$ \\
\hline $\begin{array}{l}\text { Phase } 3 \text { : } \\
\text { (Months 7-18) } \\
12 \text { monthly calls }\end{array}$ & $\begin{array}{l}\text { Maintenance of behaviour change \& } \\
\text { weight loss }\end{array}$ & $\begin{array}{l}\text { Feedback on 6-, 12- \& 18-month assessments } \\
\text { Progress review at } 9 \text { \& } 15 \text { months } \\
\text { Review \& goal-setting: } \\
\text { Role of physical activity in maintaining weight loss } \\
\text { Problem-solving } \\
\text { Social-environmental support } \\
\text { Developing lifelong habits }\end{array}$ \\
\hline
\end{tabular}

get out of the program); education on weight loss (e.g. energy balance); and skill-building (e.g. self-monitoring and goal-setting). The emphasis is on helping participants to gain the knowledge and skills necessary to achieve behaviour change and weight loss in the next phase.

Phase 2 (months 2-6) Up to 11 fortnightly calls are completed during this phase, with an emphasis on initial behaviour change, weight loss and continued confidence and skill-building. Behaviourally-specific goal setting with regard to the amount of physical activity and dietary change that is needed to achieve weight loss is the focus, along with problem-solving and continued selfmonitoring.

Phase 3: (months 7-18) This phase of the intervention involves 12 calls over 12 months (one per month) with a focus on maintenance of behaviour change and weight loss. During this phase, participants not yet reaching their initial weight loss, physical activity and/or dietary behaviour change targets are encouraged to continue to work towards these; those who have reached initial targets focus on strategies for maintaining weight loss and behaviour change. In addition to continued support from telephone counsellors, other strategies to promote maintenance include: ongoing self-monitoring, enlisting social support (from family, friends and health care providers), and use of community resources to support lifestyle change (e.g., weight loss groups, walking tracks, gym membership).

\section{Primary and secondary outcomes}

Primary outcomes are: change in weight $(\mathrm{kg})$, accelerometer-measured moderate-to-vigorous physical activity 
and glycaemic control (HbA1c). Secondary outcomes are: change in self-reported dietary and energy intake, accelerometer-measured light intensity and sedentary time, objectively measured waist circumference, percent body fat, fasting plasma glucose and blood lipids (total cholesterol, HDL-cholesterol, LDL-cholesterol, triglycerides), liver function enzymes, blood pressure, along with self-reported SCE constructs, medication use and health-related quality of life. We will also evaluate the incremental cost-effectiveness of the telephone intervention and examine demographic and health-related moderators of intervention effects and mediators consistent with the underlying theoretical basis. Related measures are described below and summarised in Table 3.

\section{Data collection}

Data are collected via objective measurements conducted in participants' homes, telephone interviews, and selfadministered questionnaires at baseline, 6-, 18-, and 24months by research staff and registered nurses blind to participants' study group. At 12 months, weight, waist circumference and accelerometer-derived physical activity are also assessed. Home visits are conducted by registered nurses and include objective measurement of: height (baseline only; Seca 214 height rod, Seca, Germany), weight, waist circumference, body composition, blood pressure and collection of blood samples for biochemical assay. In addition, details of diabetes medications (drug and dosage) and any use (yes/no) of antihypertensive and lipid-lowering medications are also collected during this visit. Telephone interviews collect self-report data on: demographics (gender, age, education, income, type and number of chronic conditions; baseline only), and validated measures of physical activity, diet, quality of life and health care use, as well as items to assess sleep, diabetes history and management, use of weight loss aids and adverse outcomes. Self-administered questionnaires are used to collect data related to the social-cognitive and environmental constructs which underpin the intervention and to assess depression. In addition to the self-reported physical activity collected via the telephone interviews, accelerometers are used to collect objectively-measured physical activity and sedentary time. Data related to intervention delivery are also tracked by telephone counsellors following each call. This includes data on call outcomes (call completion versus missed calls), call duration and call content (via a checklist of topics). Details of the measures are provided below and summarised in Table 3 .

\section{Anthropometric outcomes}

Weight loss Weight is measured without shoes or heavy clothing to the nearest $0.1 \mathrm{~kg}$ using standard calibrated scales (Model TI TBF 350, Tanita Inc., Tokyo, Japan).

Waist circumference Waist circumference is measured with a non-expandable tape to the nearest $0.5 \mathrm{~cm}$ at the superior border of the iliac crest [12,72]. Waist measurements are taken in duplicate and a third measurement taken if the first two differ by more than $1 \mathrm{~cm}$. The mean of the measurements is used.

Body composition Fat mass $(\mathrm{kg})$, fat free mass $(\mathrm{kg})$ and percent body fat are measured using foot-to-foot bioelectrical impedance analysis (Model TI TBF 350, Tanita Inc., Tokyo, Japan) in the fasted state. Body composition measurements are not performed on participants with a pacemaker.

\section{Cardio-metabolic outcomes}

Blood samples are taken early in the morning after an overnight fast (at least 10 hours), with participants instructed not to take any glucose-lowering medication prior to the assessment.

Glycaemic control $\mathrm{HbA} 1 \mathrm{c}$ is measured from whole blood samples by the high performance liquid chromatography method (Bio-Rad Variant II, Sydney, Australia). Plasma glucose is measured by the hexokinase method (Roche Modular Analyzer; Tokyo, Japan).

Blood lipids Total cholesterol, high density lipoprotein (HDL) cholesterol and triglycerides are measured by an enzymatic colorimetric assay with Roche Modular Chemistry Analyser (Tokyo, Japan). Low density lipoprotein (LDL) cholesterol is determined using the Friedewald equation [73,74].

Liver function tests Liver enzymes - alanine aminotransferase (ALT), aspartate amino-transferase (AST), lactate dehydrogenase (LDH), alkaline phosphatase (ALP), gamma glutamyl transpeptidase (GGT) - are measured using Roche Modular (Tokyo, Japan).

Blood pressure Blood pressure is measured in the seated position by a portable sphygmomanometer (Gamma G5, Heine, Germany) using the non-dominant arm and an appropriately sized cuff. Two readings are taken and a third measurement taken if the first two differ by more than $10 \mathrm{mmHg}$ systolic or $6 \mathrm{mmHg}$ diastolic, or if the first two readings are more than 140/90 $\mathrm{mmHg}$. Blood pressure is recorded as the mean of the readings taken.

Medication use Details of diabetes medication (oral medication and insulin) are collected by registered nurses from prescription containers - medication name, dose prescribed and daily quantity taken. Participants are also asked to report whether they are taking antihypertensive or lipid-lowering medications.

\section{Behavioural outcomes}

Objectively-measured physical activity and sedentary

time A dual-axis accelerometer (Actigraph model GT1M; Actigraph, LLC, Fort Walton Beach, Florida), fitted firmly around the waist by elasticised band and positioned on the right mid axillary line, is used to objectively-derive physical activity and sedentary time. Participants are instructed to wear the accelerometer 
Table 3 Summary of Measures

Anthropometric

Cardio-metabolic

Behavioural

Psychosocial-Environmental

Cost-effectiveness

\section{\#Weight}

\#Waist circumference

$\%$ body fat

\section{Glycoslyated haemoglobin}

Fasting blood glucose

Cholesterol (total, HDL, LDL)

Triglycerides

Liver function tests (ALT, AST, LDH, ALP, GGT)

Blood pressure

Diabetes medication

\#Objectively measured physical activity (PA) via accelerometer

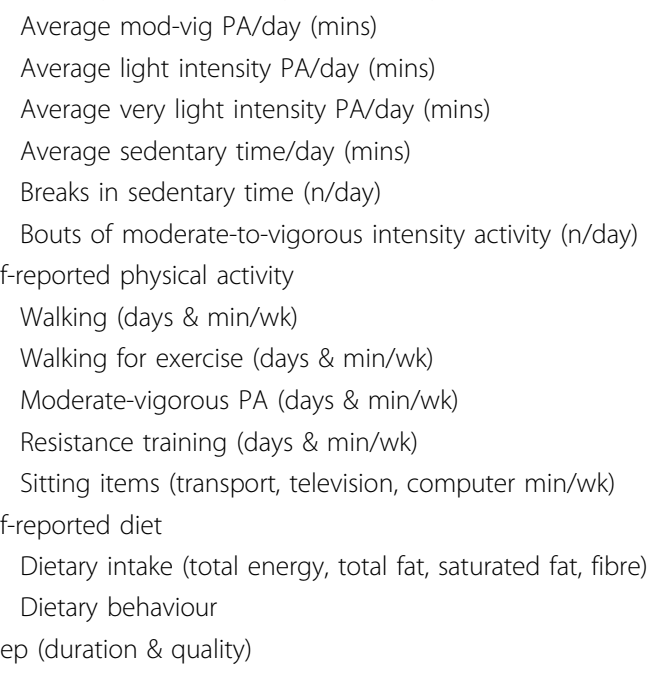

Depression

Self-efficacy

Social support

Perceptions of the neighbourhood environment

Health-related quality of life

Health care utilization

Cost to deliver intervention

Call duration

Call completion

All assessed at baseline, 6, 18 \& 24 months; \#assessed at 12 months; bold text denotes primary outcome

during all waking hours (removing for any water based activities) for a continuous period of seven days, and to record time worn in a wear-time log. The study nurse demonstrates how to wear the accelerometer and complete the wear-time log. Research staff then telephone the participant to negotiate a start date and reiterate the instructions; the accelerometer and wear-time log are then posted to participants. On the (expected) seventh day of wear, a follow-up telephone call is made by research staff to ensure adequate wear time and to prompt accelerometer return in a reply-paid envelope. The protocol for the follow-up assessment is identical with the exception that the registered nurse does not repeat the demonstration and instructions at the assessment.

Accelerometer data are collected in one minute epochs. A generic program (SAS 9.1), modified from the National Cancer Institute [75], is used to identify 
outliers and summarise daily variables. The wear time syntax of the program, based on a combination of the wear-time logs and the accelerometer data, is modified for each participant in order to maximise the accuracy of the wear time estimation. Invalid days of observation (days with $<10$ hours wear or excessive counts $\geq 20,000$ counts per minute: $\mathrm{cpm}$ ) will be discarded. Daily sedentary $(<100 \mathrm{cpm})$, very light-intensity activity $(100$ to $759 \mathrm{cpm})$, light-intensity activity $(760$ to $1951 \mathrm{cpm})$, moderate-intensity activity (1952 to $5724 \mathrm{cpm}$ ), and vigorous-intensity activity $(\geq 5725 \mathrm{cpm})[76,77]$ time are calculated and standardised for wear time using the residuals method [78]. Patterns of physical activity and sedentary time accumulation (for example, breaks in sedentary time [79] and bouts of moderate-to-vigorous intensity activity) [80] are examined. Data are reported as averages for valid days. The data collection and analytic protocol comply with the best-practice guidelines for conducting accelerometer-based activity assessments in field-based research [81].

Self-reported physical activity Self-reported physical activity is measured by the Active Australia Survey (AAS), a 6-item measure assessing frequency and total duration per week spent on walking, vigorous and moderate physical activities over the last seven days [47]. The frequency items have been adapted to ask about number of 'days per week' instead of 'sessions per week'. Total minutes of physical activity is calculated from the sum of walking, moderate and $2 \times$ vigorous minutes and truncated at 1,680 minutes per week [47]. Two items from the U.S. National Health Interview Survey (NHIS) have been adapted to assess the number of days and amount of time in the past week spent walking for exercise [82]. The AAS has been found to have acceptable validity and reliability [83], the NHIS items have shown acceptable validity [82] and both items have shown similar or greater responsiveness to change compared to a more detailed self-report instrument [84].

Self-reported resistance training Using a response format similar to that of the AAS, the number of days and total number of minutes per week of resistance training are collected using an unvalidated item [85].

Self-reported sitting time Six items are used to assess total time spent sitting in the last week across three domains - 1) transport, 2) watching television, videos or playing electronic games and 3) leisure-time computer use - asked separately for weekdays and weekend days. These items have shown good test-retest reliability (unpublished data).

Dietary intake Diet is assessed using the Anti-Cancer Council of Victoria (ACCV) Food Frequency Questionnaire (FFQ) (version 2). The FFQ includes 74 food items and six alcoholic beverage items with responses on a 10point scale $(1=$ Never to $10=3$ or more times per day $)$, four pictorial questions relating to portion size, one question on quantity of alcoholic beverages and 10 cross-check questions used to adjust for overestimation and types of food products consumed (milk, bread, spread and cheese) [86]. It was modified to ask about intake over the previous month instead of the previous 12 months and to be telephone administered instead of self-administered (participants receive a copy of the portion size pictures in the mail). Nutrient intakes are computed from FFQ responses using software developed by the ACCV based on the NUTTAB95 nutrient composition data [87]. The questionnaire estimates intakes of most nutrients accurately (within 10\%) and does not systematically under- or over-estimate against weighed records [86].

In addition to the FFQ, dietary behaviours and intakes of specific food groups will also be assessed. Servings of vegetables and fruit are assessed using items from the Australian National Nutrition Survey which have demonstrated validity against more comprehensive selfreported measures [88] and biomarkers (serum carotenoids and red-cell folate) [89]. The 20-item Fat \& Fibre Behaviour Questionniare is also administered. This questionnaire was used in our previous trial [40] and adapted from other short dietary questionnaires [90-93] to assess behaviours related to fat and fibre intake that were targeted as part of the intervention. This index has shown good two-week test-retest reliability (ICC $=0.87$ 0.89), Pearson's correlations of 0.50-0.56 for relative validity compared to FFQ and similar or higher responsiveness compared to FFQ (unpublished data).

Sleep A single item to assess sleep duration on weekdays or workdays in the past week (reported in hours and minutes) was adapted from an existing instrument with established reliability and validity [94-96]. A single item to assess sleep quality (in terms of feeling rested upon awakening; rated from $1=$ excellent to $5=$ poor) was created.

\section{Psychosocial-environmental outcomes}

Depression Measured using 9-items from the PRIMEMD Patient Health Questionnaire (PHQ) assessing depressive symptoms over the last two weeks, with items answered on a 4-point scale $(0=$ not at all; $1=$ several days; $2=$ more than half the days; $3=$ nearly every day). Items are summed such that higher scores indicate a higher depression symptom severity, which has shown good criterion validity compared to a Mental Health Professional interview $(r=0.84)$ [97].

Eating and exercise self-efficacy Measured using a 10item questionnaire that assesses confidence in ability to follow exercise and eating plans in difficult situations (e.g., confidence in exercising when sore or tired; confidence to choose healthy food options when bored) [98]. Items are answered on a scale from 0 (not at all 
confident) to 8 (extremely confident), and summed to create a 5-item eating self-efficacy scale and 5-item exercise self-efficacy scale, which have shown good internal consistency - Cronbach's $\alpha=0.87$ and 0.91, respectively [98].

Confidence in weight loss Using the format and scale above, a single item on confidence in losing weight through exercise and healthy eating was adapted for this study from the Multidimensional Diabetes Questionnaire [99].

Social support for diet and physical activity Measured using a 20-item questionnaire assessing the frequency of family and friend support over the previous three months for healthy eating and exercise (e.g. complimented you on your progress in making healthy changes to your diet; exercised with you); answered on a 5-point scale $(1=$ none of the time; $5=$ very often) [100]; and summed separately for diet and physical activity. The questionnaire was adapted to ask about support received from 'friends, family or members of your household' combined, instead of asking questions separately for support from 'friends' and from 'family.'

Perceptions of the neighbourhood environment Measured using 10-items created to assess neighbourhood attributes related to walking for exercise or transport (i. e., aesthetics, convenience, access and traffic); answered on an 11 -point scale $(-5=$ strongly disagree; $+5=$ strongly agree, with $0=$ neutral option). The items were selected or modified from existing instruments [101,102].

\section{Cost-effectiveness}

Health-related quality of life The Short-Form (SF)-12 Version 2 Health Survey [103], validated for use in Australia $[104,105]$, is used to assess health-related quality of life across eight dimensions - physical functioning, social functioning, role limitations due to physical problems, role limitations due to emotional problems, bodily pain, vitality, general health and mental health. To enable economic analysis, the SF-12 is converted to EQ$5 \mathrm{D}$ preference based utility values via an algorithm developed by Gray and colleagues [106].

Health care utilisation Measured using 9-items assessing doctor and allied health care visits and hospital stays in the past six months [107]. Dollar valuations of these resources are obtained from the Commonwealth Government schedule of re-imbursements [108] and are used in cost-effectiveness analysis.

Intervention costs Costs to deliver the intervention, not including the research/assessment components, are used in the cost-effectiveness analysis. They are tracked during trial implementation and include the cost of counsellor time, intervention materials (workbook, pedometer, stretch band, scale) and related infrastructure (i.e., office space, telephones, computers and call costs).

\section{Patient safety}

A number of strategies are used to ensure patients' safety. Intervention participants who identify new health concerns or questions about the medical management of diabetes are recommended to visit their GP to seek advice. Any participant who indicates suicidal ideation on the PHQ-9 scale is contacted by the project manager and informed that their GP will be notified and a 24-hour telephone crisis service number is provided. Adverse outcomes are also systematically monitored, as described below.

\section{Adverse outcomes monitoring system}

Adverse outcomes are assessed at each follow-up telephone interview by asking participants if they have had any new health problems since the previous contact, with the following examples provided: any new diagnoses of medical conditions or illnesses, such as a heart attack or cancer, any periods of hospitalisation or surgery, any muscle injuries, bone or joint problems, or any new symptoms or worsening of pre-existing conditions. Responses are recorded verbatim and then coded independently by two of the study investigators, first as "serious" (i.e., requiring hospitalisation) versus not, and then as "directly attributable to the study" (i.e., exercise-related pain or muscle injury, digestive disturbances related to dietary changes) versus not, with input on disagreements discussed with a researcher independent of the trial.

\section{Statistical analyses}

\section{Primary and secondary outcomes}

Data will be analysed using intention-to-treat principles. Once a participant is randomised into a study group, they will be considered a trial participant and analysed according to their allocated group, regardless of missing data for follow-ups or the amount of intervention received. Each primary and secondary outcome will be modelled using mixed linear models with random intercepts, the fixed effects of study group, time and a group by time interaction as well as baseline values (to account for regression to the mean). Potential confounders include baseline characteristics and the factors used to balance groups by minimisation. Confounders will be identified by forwards and backwards selection. Inclusion in the final model will require the addition or omission of the potential confounder to elicit a substantial change in the coefficient for the effect of intervention. A $20 \%$ change in coefficient will be considered substantial unless the coefficient is close to zero. Data analysis will be performed using [SAS/STAT] software, Version [9.2] of the SAS system for Windows. Statistical significance will be set at the conventional two-tailed 5\% level.

\section{Incremental cost-effectiveness}

A probabilistic decision analytic Markov model developed for our recent telephone-delivered lifestyle intervention trial will be adapted and used to evaluate incremental 
cost-effectiveness [42]. The structure, data requirements, methods for calibration and model evaluation are described in a recent methodological peer reviewed publication [91]. The model describes the health states relevant to intervening on weight loss, physical activity, and glycaemic control in adults with type 2 diabetes. A societal perspective is adopted and values collected for variables that describe the participant's use of acute and primary care health services, their private out of pocket expenditures and the time costs to informal carers. Patient-based production losses are not included on the cost side of the analysis but (implicitly) counted within the QALY estimation in line with current theory and recommendations [92]. The model implies the trial participants face some probability of remaining in a sub-optimal health state or transitioning to improved health states (i.e. improvements in weight, physical activity and glycaemic control) and there will be a small chance of transitioning to death. Cycle duration is based on the timing of data collection for health-related quality of life (i.e. baseline, 6, 18, and 24 months). The transition probabilities that reflect consistency with study intervention targets surrounding primary outcomes (i.e., $5 \%$ weight loss, $210 \mathrm{~min} / \mathrm{wk}$ moderate-tovigorous $\mathrm{PA},<7 \% \mathrm{HbA} 1 \mathrm{c}$ ) will be used to predict movement through the states for all cycles; this approach is shown in a previous economic analysis [42]. Costs and utility based preference scores will be estimated for each cycle and summarised to estimate change in costs and change in QALYs. The relevant ICER will be estimated and cost-effectiveness acceptability curves plotted to illustrate the probability that the intervention is cost-effective [109].

\section{Moderators and mediators of outcome}

Exploratory analyses will be conducted to determine whether there is moderation or mediation of intervention effects using previously established methods $[95,96]$. Moderator analysis will determine whether intervention effects differ across demographic (e.g. age, gender) and medical (e.g. insulin use) characteristics and will be performed by considering the statistical significance of an interaction between a potential moderator and the intervention using a Wald test.

Mediator analysis will determine whether theoretically-driven constructs and mechanisms for behaviour change do in fact mediate the intervention effects. Potential mediators will be assessed using path analysis. Point estimates and bootstrap confidence intervals of path coefficients and the product of the mediated path coefficients will be used to determine the potency, certainty and direction of any mediation effect [110].

\section{Sample size}

Effect size estimates for the proposed study take into account clinically meaningful differences and are based on published results $[24,111,112]$, and unpublished data from our recent trials. The minimum differences of interest in change from baseline to 18-months follow-up between intervention and usual care groups for our primary outcomes are: $-5 \%$ of initial body weight; +60 minutes/week for moderate physical activity; $-0.6 \%$ for HbA1c. Sample size estimates are based on the expected mean difference for physical activity, as this variable required the largest sample size. To detect a mean difference of 60 minutes per week change in accelerometer-derived moderate-to-vigorous intensity physical activity between the intervention and control groups with $90 \%$ power and $5 \%$ significance (two-tailed), assuming a standard deviation of 140 minutes (based on unpublished data), requires 115 subjects per group. Assuming an attrition rate of $30 \%$ means that 150 participants per group are required (300 participants overall). This sample size provides sufficient power $(80 \%$ or more) to detect the following intervention effects for sedentary time ( -45 minutes/day); light intensity time (+30 minutes/day); and, our secondary outcomes: $-2,000$ kJ for energy intake; $-5 \%$ for energy from fat; $-2 \%$ for energy from saturated fat; -5 to $10 \%$ for cholesterol (total, LDL-, HDL-); -15\% for triglycerides; $-1 \mathrm{mmol} / \mathrm{L}$ for fasting plasma glucose; $-5 \mathrm{mmHg}$ for systolic blood pressure; $-5 \mathrm{~cm}$ for waist circumference; and, $-2 \%$ for body fat.

\section{Discussion}

The epidemic of type 2 diabetes shows no signs of abating. Both weight loss and physical activity are independently associated with improved glycaemic control, lipids and blood pressure in type 2 diabetes [49] and are important diabetes management goals. Thus there is a need to develop, evaluate and disseminate approaches that are effective in promoting the maintenance of weight loss and physical activity. Telephone-delivered interventions show promise in this regard as they facilitate, in a cost-effective manner, [42] the repeated contacts and support necessary to promote maintenance.

The Living Well with Diabetes study is evaluating a broad reach strategy (telephone counselling), with emphasis on behavioural and physiologic outcomes, fidelity of implementation, incremental cost-effectiveness, and assessment of maintenance. These issues are important to advancing the science of mass reach approaches to weight management and health behaviour change, as well as building the evidence base for the translation of this work into population health practice.

\section{Acknowledgements}

We wish to thank the patients, general practitioners and practice staff of the Southeast Primary Healthcare Network (Logan, Australia) who are participating in the study and Diabetes Australia Queensland for their 
endorsement and provision of materials for the usual care group. We would also like to thank project staff for their integrity and commitment, Lisa Ulyate, Fiona Porter, Fiona Heys, Amy Chatwin, Natalie Doyle, Eskae vanEck, Kym Spathonis, Jane Masters, Lorinne duToit, Kasun Weerkakody. This study was supported by a National Health and Medical Research Council (NHMRC) project grant \# 511000. E Eakin is supported by a NHMRC Senior Research Fellowship \#511001, M Reeves is supported by a NHMRC Postdoctoral Training Fellowship \#389500, A Marshall is supported by a NHMRC Career Development Award \#553000, D Dunstan is supported by a VicHealth Public Health Research Fellowship, G Healy is supported by a NHMRC (\#569861)/ National Heart Foundation of Australia (PH 08B 3905) Postdoctoral Fellowship. The trial is registered with the Australian Clinical Trials Registry \#ACTRN12608000203358.

\section{Author details}

${ }^{1}$ The University of Queensland, Level 3 Public Health Building, School of Population Health, Cancer Prevention Research Centre, Herston Road, Herston, QLD, Australia. ${ }^{2}$ Queensland University of Technology, School of Public Health, Faculty of Health, Brisbane, Australia. ${ }^{3}$ Baker IDI Heart and Diabetes Institute, Melbourne, Australia. ${ }^{4}$ The University of Queensland, Centre for Diabetes and Endocrine Research, Princess Alexandra Hospital, Brisbane, Australia. ${ }^{5}$ Southeast Primary Healthcare Network, Logan, Australia.

\section{Authors' contributions}

All authors contributed to the design of the study and the writing of the manuscript. All authors read and approved the final manuscript.

\section{Competing interests}

The authors declare that they have no competing interests.

Received: 16 July 2010 Accepted: 3 August 2010

Published: 3 August 2010

\section{References}

1. Dunstan DW, Zimmet PZ, Welborn TA, de Courten MP, Cameron A, Sicree RA, Dwyer T, Colagiuri S, Jolley D, Knuiman M, Atkins R, Shaw JE, on behalf of the AusDiab Steering Committee: The rising prevalence of diabetes mellitus and impaired glucose tolerance: The Australian Diabetes, Obesity and Lifestyle Study. Diabetes Care 2002, 25:829-834.

2. Cameron AJ, Welborn TA, Zimmet PZ, Dunstan DW, Owen N, Salmon J, Dalton M, Jolley D, Shaw JE: Overweight and obesity in Australia: The 1999-2000 Australian diabetes, obesity and lifetyle study (AusDiab). Med J Aust 2003, 178:427-432.

3. Shaw JE, Sicree RA, Zimmet PZ: Global estimates of the prevalence of diabetes for 2010 and 2030. Diabetes Res Clin Pract 2010, 87:4-14.

4. Boyle JP, Honeycutt AA, Narayan KM, Hoerger TJ, Geiss LS, Chen H, Thompson TJ: Projection of diabetes burden through 2050: impact of changing demography and disease prevalence in the U.S. Diabetes Care 2001, 24:1936-1940.

5. Mathers C, Vos T, Stevenson C: The burden of disease and injury in Australia Canberra: Australian Institute of Health and Welfare 1999

6. Colagiuri S, Colagiuri R, Grainger D, Graham-Clarke P, Davey P, Fitzgerald P, Conway P: DiabCost Australia: Assessing the burden of type 2 diabetes. Diabetologia 2002, 45(Suppl 2).

7. Stratton IM, Adler Al, Neil HA, Matthews DR, Manley SE, Cull CA, Hadden D, Turner RC, Holman RR: Association of glycaemia with macrovascular and microvascular complications of type 2 diabetes (UKPDS 35): Prospective observational study. Br Med J 2000, 321:405-412.

8. Muller WA: Diabetes mellitus: Long time survival. J Insur Med 1998, 30:17-27.

9. Maggio CA, Pi-Sunyer XF: The prevention and treatment of obesity: Application to type 2 diabetes. Diabetes Care 1997, 20:1744-1766.

10. Klein S, Sheard NF, Pi-Sunyer X, Daly A, Wylie-Rosett J, Kulkarni K, Clark NG Weight management through lifestyle modification for the prevention and management of type 2 diabetes: rationale and strategies. A statement of the American Diabetes Association, the North American Association for the Study of Obesity, and the American Society for Clinical Nutrition. Diabetes Care 2004, 27:2067-2073.

11. National Health and Medical Research Council: Clinical Practice Guidelines for the Management of Overweight and Obesity in Adults. Canberra 2003.
12. National Heart Lung and Blood Institute, the North American Association for the Study of Obesity: The practical guide: identification, evaluation and treatment of overweight and obesity in adults. Bethesda, MD 2000.

13. Anderson JW, Kendall CW, Jenkins DJ: Importance of weight management in type 2 diabetes: Review with meta-analysis of clinical studies. J Am Coll Nutr 2003, 22:331-339.

14. De Fronzo RA: Pharmacologic therapy for type 2 diabetes mellitus. Ann Intern Med 1999, 131:281-303.

15. Boule NG, Haddad E, Kenny GP, Wells GA, Sigal RJ: Effects of exercise on glycaemic control and body mass in type 2 diabetes mellitus: A metaanalysis of controlled clinical trials. JAMA 2001, 286:1218-1227.

16. Marwick TH, Hordern MD, Miller T, Chyun DA, Bertoni AG, Blumenthal RS, Philippides $G$, Rocchini A: Exercise training for type 2 diabetes mellitus: impact on cardiovascular risk: a scientific statement from the American Heart Association. Circulation 2009, 119:3244-3262.

17. Glasgow RE, Eakin EG, Toobert DJ: How generalizable are the results of diabetes self-management research? The impact of participation and attrition. Diabetes Educ 1996, 22:573-585.

18. Ryan DH, Espeland MA, Foster GD, Haffner SM, Hubbard VS, Johnson KC, Kahn SE, Knowler WC, Yanovski SZ, Look AHEAD Research Group: Look AHEAD (Action for Health in Diabetes): design and methods for a clinical trial of weight loss for the prevention of cardiovascular disease in type 2 diabetes. Control Clin Trials 2003, 24:610-628.

19. Look AHEAD Research Group, Wadden TA, West DS, Delahanty L, Jakicic J, Rejeski J, Williamson D, Berkowitz Rl, Kelley DE, Tomchee C, Hill JO, Kumanyika S: The Look AHEAD study: a description of the lifestyle intervention and the evidence supporting it. Obesity (Silver Spring) 2006, 14:737-752.

20. Dunstan DW, Daly RM, Owen N, Jolley D, de Courten MP, Shaw JE, Zimmet PZ: High-intensity resistance training improves glycemic control in older patients with type 2 diabetes. Diabetes Care 2002, 25:1729-1736.

21. American Diabetes Association, Bantle JP, Wylie-Rosett J, Albright AL, Apovian CM, Clark NG, Franz MJ, Hoogwerf BJ, Lichtenstein AH, MayerDavis E, Mooradian AD, Wheeler ML: Nutrition recommendations and interventions for diabetes: a position statement of the American Diabetes Association. Diabetes Care 2008, 31(Suppl 1):61-78.

22. Norris SL, Nichols PJ, Caspersen CJ, Glasgow RE, Engelgau MM, Jack L, Snyder SR, Carande-Kulis VG, Isham G, Garfield S, Briss P, McCulloch D: Increasing diabetes self-management education in community settings. A systematic review. Am J Prev Med 2002, 22:39-66.

23. Eakin EG, Bull SS, Glasgow RE, Mason M: Reaching those most in need: $A$ review of diabetes self-managment interventions in disadvantaged populations. Diabetes Metab Res Rev 2002, 18:26-35.

24. Mayer-Davis EJ, D'Antonio AM, Smith SM, Kirkner G, Martin SL, ParraMedina D, Schultz R: Pounds off with empowerment (POWER): A clinical trial of weight management strategies for black and white adults with diabetes who live in medically underserved rural communities. $\mathrm{Am} J$ Public Health 2004, 94:1736-1742.

25. Wolf AM, Conaway MR, Crowther JQ, Hazen KY, Nadler JL, Oneida B, Bovbjerg VE: Translating lifestyle intervention to practice in obese patients with type 2 diabetes: Improving control with activity and nutrition (ICAN) study. Diabetes Care 2004, 27:1570-1576.

26. Harvey-Berino J, Pintauro S, Buzzell P, Gold EC: Effect of internet support on the long-term maintenance of weight loss. Obes Res 2004, 12:321-329.

27. Sherwood NE, Jeffrey RW, Pronk NP, Boucher JL, Hanson A, Boyle R, Brelje K, Hase $\mathrm{K}$, Chen V: Mail and phone interventions for weight loss in a managed-care setting: Weigh-to-be 2-year outcomes. Int J Obes 2006, 30:1565-1573.

28. Woollard J, Burke V, Beilin $\sqcup$, Verheijden M, Bulsara MK: Effects of a general practice-based intervention on diet, body mass index and blood lipids in patients at cardiovascular risk. J Cardiovasc Risk 2003, 10:31-40.

29. Digenio A, Mancuso J, Gerber R, Dvorak R: Comparison of methods for delivering a lifestyle modification program for obese patients: a randomized trial. Ann Intern Med 2009, 150:255-262.

30. Neve $M$, Morgan $P$, Jones $P$, Collins $C$ : Effectiveness of web-based interventions in achieving weight loss and weight loss maintenance in overweight and obese adults: a systematic review with meta-analysis. Obes Rev 2010, 11:306-321.

31. Perri $M G$, Limacher $M C$, Durning $P E$, Janicke $D M$, Lutes $L D$, Bobroff $L B$, Dale MS, Daniels MJ, Radcliff TA, Martin AD: Extended-care programs for 
weight management in rural communities: the treatment of obesity in underserved rural settings (TOURS) randomized trial. Arch Intern Med 2008, 168:2347-2354.

32. Humpel $\mathrm{N}$, Marshall AL, Iverson $\mathrm{D}$, Leslie $\mathrm{E}$, Owen $\mathrm{N}$ : Trial of print and telephone delivered interventions to influence walking. Prev Med 2004, 39:635-641,

33. Marshall AL, Bauman A, Owen N, Booth ML, Crawford DC, Marcus BH: Population-based randomised controlled trial of a stage-targeted physical activity intervention. Ann Behav Med 2003, 25:194-202.

34. Marshall AL, Bauman A, Owen N, Booth ML, Crawford DC, Marcus BH: Reaching out to promote physical activity: A statewide randomised controlled trial of a stage-targeted intervention. Am J Health Promot 2004, 19:283-287.

35. Marshall AL, Booth ML, Bauman AE: Promoting physical activity in Australian general practices: A randomised trial of health promotion advice versus hypertension management. Patient Educ Couns 2005, 56:283-290.

36. Marshall AL, Leslie E, Owen N, Bauman A: Print versus website physical activity programs: A randomised trial. Am J Prev Med 2003, 25:88-94.

37. Eakin EG, Bull SS, Riley KM, Reeves MM, McLaughlin P, Gutierrez S: Resources for health: a primary-care-based diet and physical activity intervention targeting urban Latinos with multiple chronic conditions. Health Psychol 2007, 26:392-400.

38. Marcus BH, Napolitano MA, King AC, Lewis BA, Whiteley JA, Albrecht A, Parisi A, Bock B, Pinto B, Sciamanna C, Jakicic J, Papandonatos GD: Telephone versus print delivery of an individualized motivationally tailored physical activity intervention: Project STRIDE. Health Psychol 2007, 26:401-409.

39. Eakin EG, Lawler SP, Vandelanotte C, Owen N: Telephone interventions for physical activity and dietary behavior change: a systematic review. Am J Prev Med 2007, 32:419-434.

40. Eakin E, Reeves M, Lawler S, Graves N, Oldenburg B, Del Mar C, Wilke K, Winkler E, Barnett A: Telephone counseling for physical activity \& diet in primary care patients. Am J Prev Med 2009, 36:142-149.

41. Eakin E, Reeves M, Winkler E, Lawler S, Owen N: Maintenance of physical activity and dietary change following a telephone-delivered intervention. Health Psychol

42. Graves N, Barnett AG, Halton KA, Veerman JL, Winkler E, Owen N, Reeves MM, Marshall A, Eakin E: Cost-effectiveness of a telephonedelivered intervention for physical activity and diet. PLOS One 2009, 4 e7135.

43. Fjeldsoe BS, Miller YD, Marshall AL: MobileMums: a randomized controlled trial of an SMS-based physical activity intervention. Ann Behav Med 2010, 39:101-111.

44. Obesity and overweight. [http://www.who.int/dietphysicalactivity/ publications/facts/obesity/en/print.html].

45. Altman DG, Bland JM: Treatment allocation by minimisation. BMJ 2005, 330:843.

46. Scott NW, McPherson GC, Ramsay CR, Campbell MK: The method of minimization for allocation to clinical trials. a review. Control Clin Trials 2002, 23:662-674.

47. Australian Institute of Health and Welfare: The Active Australia Survey: A Guide and Manual for Implementation, Analysis and Reporting. Canberra 2003.

48. Minim: Allocation by minimisation in clinical trials. [http://www-users.york. ac.uk/ mb55/guide/minim.htm].

49. Donnelly JE, Blair SN, Jakicic JM, Manore MM, Rankin JW, Smith BK: American College of Sports Medicine Position Stand. Appropriate physical activity intervention strategies for weight loss and prevention of weight regain for adults. Med Sci Sports Exerc 2009, 41:459-471.

50. Diabetes Management in General Practice - Guidelines for Type 2 Diabetes - 2010/11. [https://www.racgp.org.au/Content/NavigationMenu/ ClinicalResources/RACGPGuidelines/Diabetesmanagement/ 201011 diabetesmanagementingeneralpractice.pdf].

51. Lowe M, Foster G, Kerzhnerman I, Swain R, Wadden T: Restrictive dieting vs. "undieting" effects on eating regulation in obese clinic attenders. Addict Behav 2001, 26:253-266.
52. Wing RR, Hill JO: Successful weight loss maintenance. Annu Rev Nutr 2001, 21:323-341.

53. Andersen RE, Wadden TA, Bartlett SJ, Zemel B, Verde TJ, Franckowiak SC Effects of lifestyle activity vs structured aerobic exercise in obese women: a randomized trial. JAMA 1999, 281:335-340.

54. Dunstan DW, Vulikh E, Owen N, Jolley D, Shaw JE, Zimmet PZ: Community center-based resistance training for the maintenance of glycemic control in adults with type 2 diabetes. Diabetes Care 2006, 29:2586-2591.

55. Nelson ME, Rejeski WJ, Blair SN, Duncan PW, Judge JO, King AC, Macera CA Castaneda-Sceppa C: Physical Activity and Public Health in Older Adults: Recommendation from the American College of Sports Medicine and the American Heart Association. [Report]. Med Sci Sports Exerc 2007, 39:1435-1445.

56. Healy GN, Dunstan DW, Salmon J, Cerin E, Shaw JE, Zimmet PZ, Owen N: Objectively measured light-intensity physical activity is independently associated with 2-h plasma glucose. Diabetes Care 2007, 30:1384-1389.

57. Hu FB, Li TY, Colditz GA, Willett WC, Manson JE: Television watching and other sedentary behaviors in relation to risk of obesity and type 2 diabetes mellitus in women. JAMA 2003, 289:1785-1791.

58. Lahmann PH, Friedenreich C, Schuit AJ, Salvini S, Allen NE, Key TJ, Khaw KT, Bingham S, Peeters PH, Monninkhof E, Bueno-de-Mesquita HB, Wirfält $\mathrm{E}_{\text {, }}$ Manjer J, Gonzales CA, Ardanaz E, Amiano P, Quirós JR, Navarro C, Martinez C, Berrino F, Palli D, Tumino R, Panico S, Vineis P, Trichopoulou A, Bamia C, Trichopoulos D, Boeing H, Schulz M, Linseisen J, et al: Physical activity and breast cancer risk: the European Prospective Investigation into Cancer and Nutrition. Cancer Epidemiol Biomarkers Prev 2007, 16:36-42.

59. Dunstan DW, Barr EL, Healy GN, Salmon J, Shaw JE, Balkau B, Magliano DJ, Cameron AJ, Zimmet PZ, Owen N: Television viewing time and mortality: the Australian Diabetes, Obesity and Lifestyle Study (AusDiab). Circulation 2010, 121:384-391.

60. Thorp AA, Healy GN, Owen N, Salmon J, Ball K, Shaw JE, Zimmet PZ, Dunstan DW: Deleterious associations of sitting time and television viewing time with cardiometabolic risk biomarkers: Australian Diabetes, Obesity and Lifestyle (AusDiab) study 2004-2005. Diabetes Care 2010, 33:327-334.

61. Franz MJ, Bantle JP, Beebe CA, Brunzell JD, Chiasson JL, Garg A, Holzmeister LA, Hoogwerf B, Mayer-Davis E, Mooradian AD, Purnell JQ, Wheeler M: Evidence-based nutrition principles and recommendations for the treatment and prevention of diabetes and related complications. Diabetes Care 2003, 26(Suppl 1):51-61.

62. Delbridge E, Prendergast L, Pritchard J, Proietto J: One-year weight maintenance after significant weight loss in healthy overweight and obese subjects: does diet composition matter? Am J Clin Nutr 2009, 90:1203-1214.

63. Foster G, Wyatt H, Hill J, McGuckin B, Brill C, Mohammed B, Szapary P, Rader D, Edman J, Klein S: A randomized trial of a low-carbohydrate diet for obesity. N Engl J Med 2003, 348:2082-2090.

64. Stern L, lqbal N, Seshadri P, Chicano KL, Daily DA, McGrory J, Williams M, Gracely EJ, Samaha FF: The effects of low-carbohydrate versus conventional weight loss diets in severely obese adults: one-year followup of a randomized trial. Ann Intern Med 2004, 140:778-785.

65. Position Statement on dietary fats and dietary sterols for cardiovascular health. [http://www.heartfoundation.org.au/SiteCollectionDocuments/ Dietary\%20fats\%20position\%20statement\%20LR.pdf].

66. Wyatt HR, Grunwald GK, Mosca CL, Klem ML, Wing RR, Hill JO: Long-Term Weight Loss and Breakfast in Subjects in the National Weight Control Registry. Obesity (Silver Spring) 2002, 10:78-82.

67. Wing RR, Phelan S: Long-term weight loss maintenance. Am J Clin Nutr 2005, 82:222S-225S.

68. Glasgow RE, Toobert DJ, Barrera M, Strycker LA: The Chronic Illness Resources Survey: cross-validation and sensitivity to intervention. Health Educ Res 2005, 20:402-409.

69. Foreyt JP, Poston WS: The role of the behavioral counselor in obesity treatment. J Am Diet Assoc 1998, 98:27-30.

70. Emmons KM, Rollnick S: Motivational interviewing in health care settings. Opportunities and limitations. Am J Prev Med 2001, 20:68-74.

71. Eakin EG, Reeves MM, Lawler SP, Oldenburg B, Del Mar C, Wilkie K, Spencer A, Battistutta D, Graves N: The Logan Healthy Living Program: a 
cluster randomized trial of a telephone-delivered physical activity and dietary behavior intervention for primary care patients with type 2 diabetes or hypertension from a socially disadvantaged community rationale, design and recruitment. Contemp Clin Trials 2008, 29:439-454

72. Ross R, Berentzen T, Bradshaw A, Janssen I, Kahn H, Katzmarzyk P, Kuk J, Seidell J, Snijder M, Sørensen T, Després J: Does the relationship between waist circumference, morbidity and mortality depend on measurement protocol for waist circumference? Obes Rev 2008, 9:312-325.

73. Friedewald WT, Levy Rl, Fredrickson DS: Estimation of the concentration of low-density lipoprotein cholesterol in plasma, without use of the preparative ultracentrifuge. Clin Chem 1972, 18:499-502.

74. Fukuyama N, Homma K, Wakana N, Kudo K, Suyama A, Ohazama H, Tsuji C, Ishiwata K, Eguchi Y, Nakazawa H, Tanaka E: Validation of the Friedewald Equation for Evaluation of Plasma LDL-Cholesterol. J Clin Biochem Nutr 2008, 43:1-5.

75. SAS Programs for Analyzing NHANES 2003-2004 Accelerometer Data. [http://riskfactor.cancer.gov/tools/nhanes_pam/].

76. Freedson PS, Melanson E, Sirard J: Calibration of the Computer Science and Applications, Inc. accelerometer. Med Sci Sports Exerc 1998, 30:777-781.

77. Matthew CE: Calibration of accelerometer output for adults. Med SCi Sports Exerc 2005, 37:512-522

78. Willett W, Stampfer MJ: Total energy intake: implications for epidemiologic analyses. Am J Epidemiol 1986, 124:17-27.

79. Healy GN, Dunstan DW, Salmon J, Cerin E, Shaw JE, Zimmet PZ, Owen N: Breaks in sedentary time: beneficial associations with metabolic risk. Diabetes Care 2008, 31:661-666.

80. Troiano RP, Berrigan D, Dodd KW, Mâsse LC, Tilert T, McDowell M: Physical activity in the United States measured by accelerometer. Med Sci Sports Exerc 2008, 40:181-188.

81. Matthew CE, Hagströmer M, Pober DM, Bowles HR: Best practices for using physical activity monitors in population-based research. Med Sci Sports Exerc

82. Johnson MF, Sallis JF, Hovell MF: Self-report assessment of walking: Effects of aided recall instructions and item order. Measurement in Physical Education and Exercise Science 2000, 4:141-155.

83. Brown WJ, Trost SG, Bauman A, Mummery K, Owen N: Test-retest reliability of four physical activty measures used in population surveys. I Sci Med Sport 2004, 7:205-215.

84. Reeves MM, Marshall AL, Winkler E, Owen N, Eakin EG: Measuring physical activity change in broad-reach intervention trials. Journal of Physical Activity and Health 2010, 7:194-202.

85. Australian Diabetes, Obesity and Lifestyle Survey. [http://www.diabetes. com.au/pdf/AusDiab_General_Questionnaire_04_05.PDF].

86. Hodge A, Patterson A, Brown W, Ireland P, Giles G: The Anti Cancer Council of Victoria FFQ: Relative validity of nutrient intakes compared with weighed food records in young to middle-aged women in a study of iron supplementation. Aust N Z J Public Health 2000, 24:576-583.

87. Lewis J, Milligan G, Hunt A: NUTTAB95 Nutrient Data Table for Use in Australia Canberra: Australian Government Publishing Service 1995.

88. Rutishauser IHE, Webb K, Abraham B, Allsopp R: Evaluation of short dietary questions from the 1995 National Nutrition Survey. Canberra 2001.

89. Coyne T, Ibiebele TI, McNaughton S, Rutishauser IHE, O'Dea K, Hodge AM, McClintock C, Findlay MG, Lee A: Evaluation of brief dietary questions to estimate vegetable and fruit consumption using serum carotenoids and red-cell folate. Public Health Nutrition 2007, 8:298-308.

90. Brazier J, Roberts J, Deverill M: The estimation of a preference-based measure of health from the SF-36 Health Survey. J Health Econ 2002, 21:271-292.

91. Graves N, McKinnon L, Reeves M, Scuffham P, Gordon L, Eakin E: Costeffectiveness analyses and modelling the lifetime costs and benefits of health-behaviour interventions. Chronic IIIn 2006, 2:97-107.

92. Schulpher M: The role and estimation of productivity costs in economic evaluation. Economic evaluation in health care: Merging theory with practice Oxford: Oxford University PressDrummond M, McGuire A 2001, Chapter 5.

93. Ware JE, Snow K, Kosinski M, Gandek MS: SF36 Health Survey - Manual and Interpretation Guide Boston: Nimrod Press 1997.

94. Gottlieb D, Punjabi N, Newman A, Resnick H, Redline S, Baldwin C, Nieto F: Association of sleep time with diabetes mellitus and impaired glucose tolerance. Arch Intern Med 2005, 165:863-867.
95. Gottlieb D, Redline S, Nieto F, Baldwin C, Newman A, Resnick H, Punjabi N: Association of usual sleep duration with hypertension: the Sleep Heart Health Study. Sleep 2006, 29:1009-1014.

96. Stamatakis K, Brownson R: Sleep duration and obesity-related risk factors in the rural Midwest. Prev Med 2008, 46:439-444.

97. Spitzer RL, Kroenke K, Williams JB, the Patient Health Questionnaire Primary Care Study Group: Validation and utility of a self-report version of PRIMEMD: The PHQ primary care study. JAMA 1999, 282:1737-1744.

98. Linde J, Utter J, Jeffery R, Sherwood N, Pronk N, Boyle R: Specific food intake, fat and fiber intake, and behavioral correlates of BMI among overweight and obese members of a managed care organization. Int $\mathrm{J}$ Behav Nutr Phys Act 2006, 3:42.

99. Talbot F, Nouwen A, Gingras J, Gosselin M, Audet J: The assessment of diabetes-related cognitive and social factors: the Multidimensional Diabetes Questionnaire. J Behav Med 1997, 20:291-312.

100. Sallis JF, Grossman RM, Pinski RB, Patterson TL, Nader PR: The development of scales to measure social support for diet and exercise behaviors. Prev Med 1987, 16:825-836.

101. Cerin E, Saelens BE, Sallis JF, Frank LD: Neighborhood Environment Walkability Scale: validity and development of a short form. Med Sci Sports Exerc 2006, 38:1682-1691.

102. Humpel N, Marshall AL, Leslie E, Bauman A, Owen N: Changes in neighborhood walking are related to changes in perceptions of environmental attributes. Ann Behav Med 2004, 27:60-67.

103. Ware JE, Kosinski M, Keller SD: A 12-Item Short-Form Health Survey: Construction of scales and preliminary tests of reliability and validity. Med Care 1996, 34:220-233.

104. Sanderson K, Andrews G: The SF-12 in the Australian population: crossvalidation of item selection. Aust N Z J Public Health 2002, 26:343-345.

105. Tucker G, Adams R, Wilson D: New Australian population scoring coefficients for the old version of the SF-36 and SF-12 health status questionnaires. Qual Life Res 2010, 4:4.

106. Gray AM, Rivero-Arias O, Clarke PM: Estimating the association between SF-12 responses and EQ-5 D utility values by response mapping. Med Decis Making 2006, 26:18-29.

107. Lorig K, Stewart A, Ritter P, Gonzalez V, Laurent D, Lynch J: Outcome measures for health education and other health care interventions California: Sage Publications 1996.

108. Medicare Benefits Schedule. [http://www.health.gov.au/internet/ mbsonline/publishing.nsf/Content/Downloads-201005].

109. Fenwick E: Cost-effectiveness acceptability curves: Facts, fallacies and frequently asked questions. Health Econ 2004, 13:405-415.

110. Shrout $P E$, Bolger $N$ : Mediation in experimental and nonexperimental studies: New procedures and recommendations. Psychological Methods 2002, 7:422-445.

111. Ash S, Reeves MM, Bauer J, Dover T, Vivanti A, Leong C, O'Moore Sullivan T, Capra S: A randomised control trial comparing lifestyle groups, individual counselling and written information in the management of weight and health outcomes over 12 months. Int J Obes 2006, 30:1557-1564

112. Ash S, Reeves MM, Yeo S, Morrison G, Carey D, Capra S: Effect of intensive dietetic interventions on weight and glycaemic control in overweight men with type II diabetes: A randomised trial. Int J Obes 2003, 27:797-802.

\section{Pre-publication history}

The pre-publication history for this paper can be accessed here: http://www.biomedcentral.com/1471-2458/10/452/prepub

\section{doi:10.1186/1471-2458-10-452}

Cite this article as: Eakin et al: Living Well with Diabetes: a randomized controlled trial of a telephone-delivered intervention for maintenance of weight loss, physical activity and glycaemic control in adults with type 2 diabetes. BMC Public Health 2010 10:452. 